\title{
Climatic Induced Snowpack Surfaces on Lebanon's Mountains
}

\author{
Amin Shaban ${ }^{1, *}$, Talal Darwich ${ }^{1}$, Laurent Drapeau ${ }^{2}$ and Simon Gascoin ${ }^{2}$ \\ ${ }^{I}$ National Council for Scientific Research, Remote Sensing Center, Beirut, Lebanon \\ ${ }^{2}$ Centre d'Etudes Spatiales de la Biosphère, CESBIO, Toulouse cedex 9, Toulouse, France
}

\begin{abstract}
There are tremendous aspects of water resources in Lebanon where the surface water sources are the most exploited. However, snow is still the major water aspect that plays a role in feeding groundwater, springs and rivers. This water resource has been ignored since long-time and it was considered only for tourism. Nevertheless, the recently existed challenges on water supply in the region, notably the challenging climatic variability, makes it necessary to monitor the behavior and dynamics of snowpack on the mountainous regions of Lebanon. Therefore, several studies have been carried out in this respect, focusing on the use of space observations along several time series. While, few concerns were given to the physical characteristic and behavior of snow melt that resulting water flow regime. This study includes two major components of investigation. These are: the analysis of remotely sensed data to monitor snow cover area and the direct investigation of snow samples in the field to measure the melting rate and patterns. Therefore, daily MODIS satellite images, with moderate spatial resolution, were analyzed to detect any changing in the snow cover area, as well as to deduce the accumulation and melting regime. Whereas, field investigations were applied to 275 sites with different altitudes, dates and terrain aspects. The measures were analyzed to identify the relationship between snow cover dynamic, snow materials characteristics and the physical setting. Thiswill be a helpful tool to identify the climate control on the snowpack; in addition, it contributes for new inputs on water resource management approaches, notably in the view of changing climatic regime.
\end{abstract}

Keywords: Climatic induction, snowmelt, water recharge, Mount-Lebanon.

\section{INTRODUCTION}

Lebanon is located in the Middle East region with an area of about $10452 \mathrm{~km}^{2}$. However, it is characterized by a unique physiographic setting where two mountain chains (Mount Lebanon and Anti Lebanon) extend parallel to the Mediterranean, and they are separated by the Bekaa plain, a wide land depression (Fig. 1). The remarkable mountains morphology distinguishes Lebanon from the surrounding regions. Thus, the positioning of these mountain chains makes Lebanon as a climatic barrier that receives cold and wet air masses from west and condensate them before they precipitate as rainfall and snow. Hence, rainfall in Lebanon ranges between $700 \mathrm{~mm}$ in the coastal zone and $1500 \mathrm{~mm}$ on the top mountains (i.e. highest crests). While, snow covers annually more than $25 \%$ of Lebanon's territory. This is in turn reflected on the amount of water in rivers and springs, and thus Lebanon occupies 15 issuing rivers (but relatively short ones), more than 2000 major springs (>10l/sec discharge) and a number of groundwater potential aquifers and waterbearing karstic conduits.

Lebanon was considered as a water tower country. However, the current status does not reflect this phenomenon, and this is due mainly to existing shortage in water supply as a

*Address correspondence to this author at the National Council for Scientific Research, Remote Sensing Center, Beirut, Lebanon;

Tel. +961-4-409845; Fax: +961-4-409847

Email: geoamin@gmail.com result of population growth and the changing climatic conditions that witnessed lately as challenging and uncontrolled geo-environmental parameters.

Even though, water availability in Lebanon is estimated at $1350 \mathrm{~m}^{3} /$ capita/year, and water demand is about $220 \mathrm{~m}^{3} /$ capita/year, yet there is an abrupt water shortage [1]. There is excessive use of water; notably in the absence of governmental control. This has been exacerbated lately when the regular rainfall patterns have been changed to torrential rain, and this is accompanied with temperature increase, while, the anthropogenic impact exaggerated the problem. There is increasing demand aspects of water use due to additional human requirements, as well as to the increased nonaccounted for water, which has been developed lately due to water loss before any utilization. Consequently, the consumption of water in the capital Beirut (for example) was 30, 50, 84, 112 and $200 / /$ day/ capita for the years 1870,1912 , 1944, 1959 and 2007; respectively [2]. This indicates a yearly increase of about 1.2 //day/capita.

In combination with the oscillating meteorological conditions; however, the general physical setting of Lebanon acts on the regime water flow and storage. Therefore, the steep sloping terrain (i.e. slope gradient exceeds $150 \mathrm{~m} / \mathrm{km}$ ) of the mountain surfaces increases the flow rate of water, which may reach to $5 \mathrm{~m}$ per second (equivalent to $18 \mathrm{~km} /$ hour). Thus, the running water from the top mountain chains needs only few hours to reach the outlet and discharge in the Mediterranean Sea; therefore, water is lost mostly before any po- 


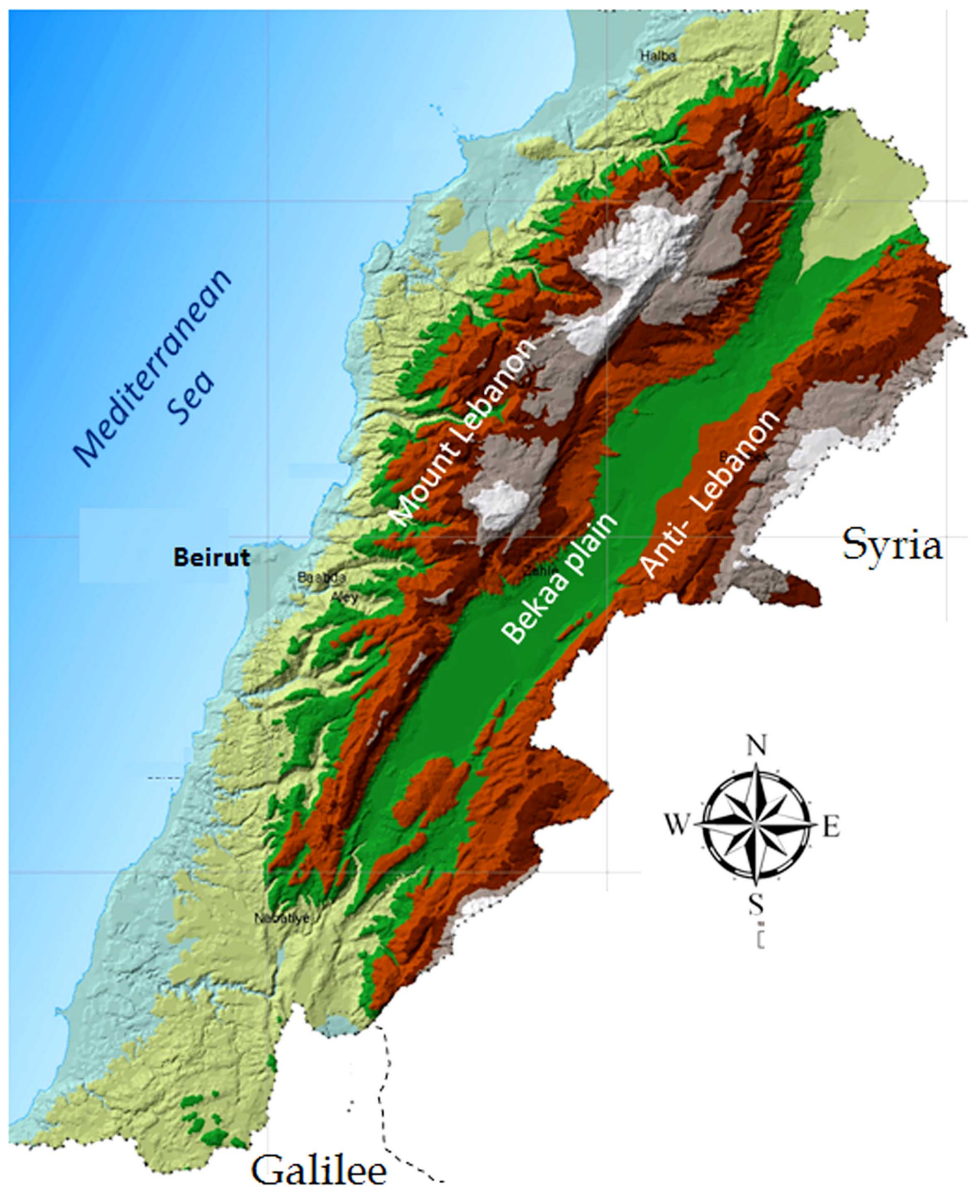

Fig. (1). The major geomorphologic units of Lebanon.

tential exploitation. Considering this hydrologic phenomenon, water from snowmelt remains the main feeding water source all year long. This is attributed to the uniform and slow melting of snow, which gives a chance for melted water to percolate into rock substratum, and thus it replenishes groundwater, rivers and springs which last discharging permanently. In this respect, water from snowmelt is believed to be the major feeding source for rivers, springs and groundwater. Abd EL-Al (1953) [3] estimated that more than $60 \%$ of Ibrahim River water, a major coastal Lebanese river, is derived from snowmelt. Shaban et al., (2004) [4] estimated that 1100 million $\mathrm{m}^{3}$ of water is resulted from snowmelt on Mount-Lebanon.

There are several physical and anthropogenic factors influencing the snowpack in Lebanon, notably during the last few decades. Therefore, the increased temperature rate was estimated at about $1.8{ }^{\circ} \mathrm{C}$, as reported between 1963 and 2009 [1]. The increased temperature acts in accelerating the melting rate of snowpack and this has been reflected on several hydrologic processes (e.g. floods, erosion, infiltration, etc). In addition, there is a clear negative human interference on snow cover areas on the high mountain chains where people misuse these areas and then interrupting the flow regime of the melting snow [5].

Studies on snow in Lebanon are still in the initial stage and concerns have been given lately to snow when water shortage has been exacerbated. Space observations and more specifically the use of satellite images enable investigating the spatial distribution of snow cover. This has been carried out in this study where MODIS satellite images were processed to measure the spatial distribution of snow on the Lebanese mountain chains over different periods of time. It followed by comparative analysis for snow cover area over the last few decades. This can be used as an evidence to induce climate change, notably that snow represents meteorological and hydrological components at the same time. Moreover, this study investigated the results of the snowpack samples which were tested in-situ to deduce the physical characteristics of snow crystals and then attributed to the existing climatic and physiographic setting.

\section{MATERIAL AND METHODS}

There are several methods used to investigate snowpack according to the objectives of investigation. Thus, there are studies which treat only the snow material and crystal arrangement [6-9]; while other studies investigate the spatial coverage of snow by using remotely sensed data [10-12]. However, the current study combined the two approaches aspects of analysis, and thus it includes: 1) monitoring snow cover by remotely sensed tools, and this includes the cover area of snow and accumulation/melting patterns, and 2) Insitu investigation to identify snow depth and density, as well as other physical characteristics an empirical comparison has 
Table 1. Major bands of satellite sensors and their utility in snowpack investigation.

\begin{tabular}{|c|c|c|c|}
\hline \multirow{2}{*}{ Snow Property } & \multicolumn{2}{c|}{ Bands } \\
\cline { 2 - 4 } & Visible/ Near Infrared (V/NIR) & Thermal Infrared \\
& (TIR) & Some errors & Microwave* \\
\hline \hline Cover area & Accurate measures & Eccurate measures \\
\hline Depth & Snow sheets can be detected & Low accuracy & Shallow depth (<40cm) is measurable \\
\hline Snow/water equivalent & Slightly accurate & Almost measurable \\
\hline Dissipation & \multicolumn{2}{|c|}{ Identifiable } & Slightly identifiable \\
\hline Melting patterns & \multicolumn{2}{|c|}{ Detected with difficulty } & Erroneous \\
\hline Albedo & \multicolumn{2}{|c|}{ Erroneous } & Slightly identified \\
\hline Crystal property & \multicolumn{2}{|c|}{} \\
\hline
\end{tabular}

*The same as Radar

been applied between these parameters. This will compose a comprehensive figure on snow distribution and its characteristics.

In this study, the selection of these investigations has been considered because in Lebanon, field measures on snowpack were applied only on snow depth while the other characteristics were not accounted. Also, the monitoring of snow cover area from space is often carried out, but only to specific regions of the Lebanese mountains or it is applied for limited time period, and not as in this study.

\subsection{Monitoring Snow Cover}

The use of space techniques has been evidenced as the most feasible application to monitor snow cover and its accumulation/melting regime. They have become well-known tool for snow observation and analysis, since these techniques can cover vast areas and which can be also studied in short time. Hence, sensors are fixed on satellites to capture a miscellany of images with diverse of optical characteristics to detect the existing objects on terrain surface.

Accordingly, snow has defined optical characteristics that can be investigated on the satellite images through the selected bands of the sensors. Therefore, some bands can identify specific snowpack characteristics as shown in Table 1. In addition, the application of spectral bands ordering can make a support for the field measure.

There are many specifications which are considered while selecting satellite images for further processing. These depend on the purpose needed. However, the spatial resolution, which represents the capability to distinguish features on the images, as well as the duration of satellite rotation around the same locality on Earth's surface (i.e. re-visit time) are the most two significant specifications. Accordingly, for snow observatory, satellite images of moderate to low resolution can be used to recognize the areal extent of snowpack, since they are characterized by short re-visit time. This can be supported by high resolution satellite images for more discrimination.
In this study MODIS satellite images have been analyzed using ERDAS-Imagine software, which is dedicated for satellite image processing. The Moderate Resolution Imaging Spectro-radiometer (MODIS) has two image products named as MODIS-Terra (MOD10A2), and MODIS-Aqua (MYD10A2). They view the entire Earth's surface every 1 to 2 days, acquiring data in 36 spectral bands, or groups of wavelengths. $(0.4 \mu \mathrm{m}$ to $14.5 \mu \mathrm{m})$ with spatial resolutions of $250 \mathrm{~m}$ (bands 1-2), 500m (bands 3-7) and 1000m (bands 836). These data improve the understanding of global dynamics and processes occurring on land and oceans. In addition, MODIS images have swath width $2030 \mathrm{~km} \mathrm{x} 1354 \mathrm{~km}$ (rows/columns).

For the subject matter of this study, MODIS-Terra images were downloaded from Goddard Space Flight Center "DISC" website of the NASA Agency. For snowpack identification, MODIS data testing depends on the reflectance criteria in the visible and near-infrared (NIR) spectral bands. The identification of snowpack can be deduced from the global criteria for snow recognition, entitled as Normalized Snow Difference Index (NDSI). Therefore, if a pixel passes that group of tests, then it is identified as snowpack [13]

For detailed investigation; however, very high resolution satellite images (i.e. Landsat TM with $30 \mathrm{~m}$ resolution or Aster with $15 \mathrm{~m}$ ) were used for comparing snow surface distribution and spatial density with those obtained from MODIS images. In this regard, the differentiation between snowpack and clouds was done from the combination between the two MODIS products (i.e. Terra and Aqua).

In this study, the time interval between July 2000 and June 2012 was investigated on MODIS images. The selection of this interval depends on data availability. Thus, MODIS data was retrieved on daily basis over the whole time interval, when the area of snow cover was calculated in order to induce the dynamics of snow accumulation and melting. Nevertheless, there are no ground or meteorological measures for the snow surface area from other sources to be compared with data obtained in this study, but the limits of snow area were investigated in the file survey to verify the reliability of snow cover identified from satellite images. 


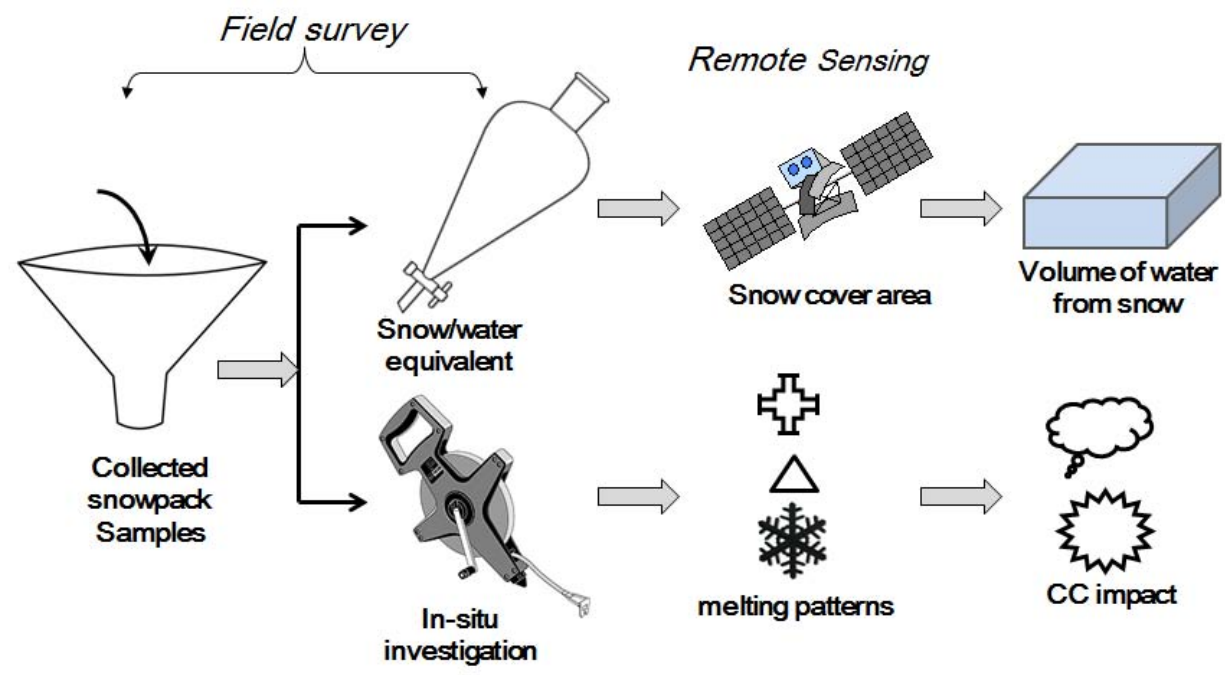

Fig. (2). Schematic figure showing the major components the study.

\subsection{Filed Surveys}

Field surveys on different localities, of the mountainous regions and sometimes on low-lands depending on snow distribution, were one of the fundamental tasks in this study. It was supplementary to the information and measures obtained from satellite images, as well as field surveys were done to investigate aspects of melting patterns of snowpack, which are related to theexisting climatic conditions.

In the field surveys, In-situ measures were carried out at different times (weekly to tens of days) over three years (2010-2013). This covered 275 localities with diverse physiographic aspects including different altitudes and slopes. During filed surveys, coordinates and temperature were primarily recorded in each locality. Thus, two main aspects of investigation were sought in this study as follows (Fig. 2):

1. Calculating the water volume derived from snowpack samples, which represents the average water volume derived from melting snow in different localities. This needs to measure two main variables, the total volume of snowpack $\left(S_{v}\right)$ and the snow/water equivalent $\left(S W_{e}\right)$ or density (i.e. percentage of water to snow). The volume of snowpack also composes two variables, the total area of snowpack $\left(A_{m}\right)$ and average depth $\left(D_{a}\right)$ according to the formula below.

$$
\mathrm{S}_{\mathrm{v}}=\mathrm{A}_{\mathrm{m}} \times \mathrm{D}_{\mathrm{a}}
$$

The area was calculated from MODIS satellite images, while the snow depth was a part of field surveys over the three years, and it was measured whether on snowpack exposures (exposed snow) or by drilling boreholes for uncovered snow at depth.

According to the snow/water equivalent $\left(S W_{e}\right)$ or density, snow samples were collected directly in vessels with defined volumes; then the volume of water in vessels was calculated after snow melts. This enabled measuring the ration of snow to water, which is the density or $S W_{e}$.

Therefore, the total water volume $\left(W_{v}\right)$ derived from snowpack in the entire area can be calculated according to the formula below. This has been applied for the 12 years investigated in this study, where the median snow cover was encountered.

$$
\mathrm{W}_{\mathrm{v}}=\left(\mathrm{A}_{\mathrm{m}} \times \mathrm{SWe} \times \mathrm{D}_{\mathrm{a}}\right)
$$

2. Identifying the melting patterns and melting rate of snowpack in the view of the increased temperature. This was also investigated in the field. Thus, three sites with different physical characteristics were selected for detailed investigation. Thus, snow patterns that configure the melting aspects were identified and manifested according to different terrain characteristics. While, the melting rate was experimentally obtained. This was applied on the sinkholes located in the area, since they compose restricted shapes with known dimensions (Fig. 3). Therefore, the dimensions of the snowpack, including the diameter, depth and the density in the selected sinkholes, were measured at defined time intervals (mostly weekly), and the decrease in volume of snowpack was measured and then converted into volume of water, since the snowpack density was previously calculated too.

\section{RESULTS AND DISCUSSION}

In consistent with the objectives of snowpack investigation in this study; however, two major aspects of analysis were carried out. They are concerned mainly with the snow accumulation and de-accumulation behaviour. The first exposes the snow cover regime over the selected time interval in order to figure out if the whole trend is ascending or descending and this is related with the precipitation and temperature rates at the selected time interval. While, the second aspect of analysis deals with major hydrologic process of snow melt. Both aspects of analysis were viewed from the climatic control on snowpack behaviour.

\subsection{Snow Cover Area}

Following the above approaches for snowpack identification from satellite images; it enabled calculating the area of 


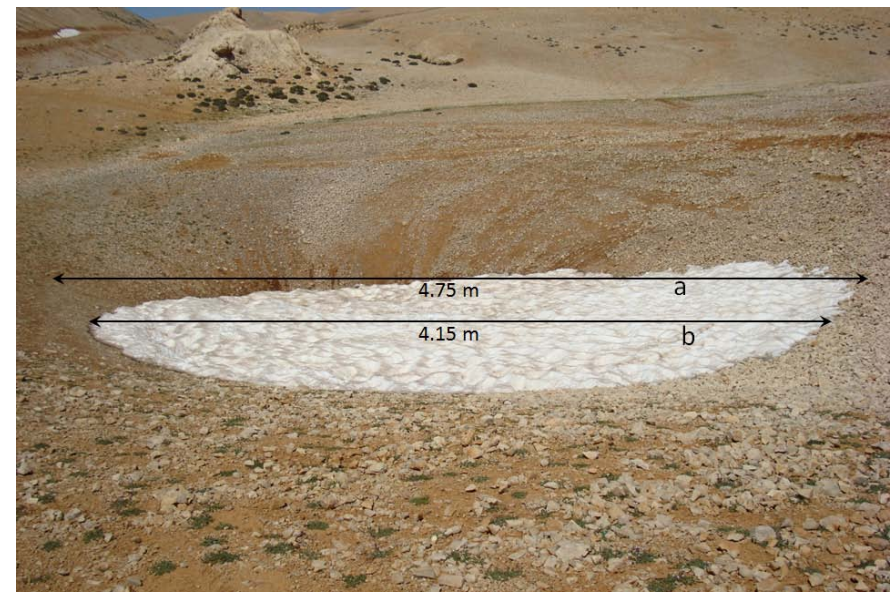

Fig. (3). Measuring the changes in snowpack as indicator for the melting rate (a) the sinkhole with 4,75m diameter and (b) the same sinkhole after one week, with $4.15 \mathrm{~m}$.

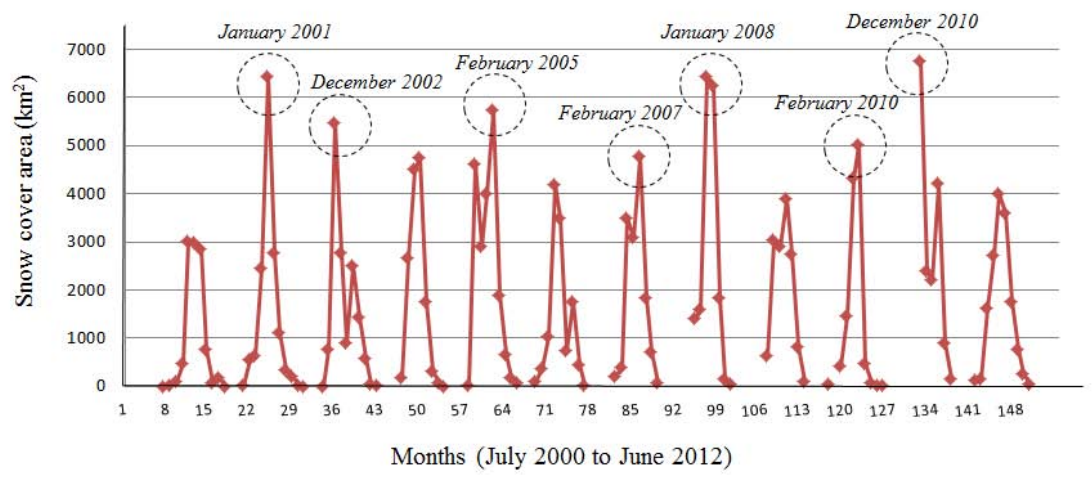

Fig. (4). Snow cover over Lebanon between July 2000 and June 2012 as detected from MODIS satellite images.

snow cover, which was diverted to average monthly data over the 12 years for the duration between July 2000 and June 2012. (Fig. 4) shows the trends of snow cover area as identified on MODI-Terra satellite images $(250 \mathrm{~m}$ spatial resolution). It is obvious that the maximum snow cover is frequently existed between December and February. Also, the maximum snow cover reaches to more than $6000 \mathrm{~km}^{2}$ in some years (e.g. 2001, 2008 and 2010), which is equivalent to two-third of the Lebanese territory $\left(10452 \mathrm{~km}^{2}\right)$. Thus, the average calculated value of the maximum snow cover values over the 12 years is found to be about $5040 \mathrm{~km}^{2}$, which is about half of the Lebanon's area. However, out of the 12 investigated years, it was found that snow started in October and November equally. While the average snow cover is estimated at about $1695 \mathrm{~km}^{2}$.

The established trend reveals that some years has only one major snowing peak (e.g. years 2001, 2008 and 2010), while other years have two peaks (e.g. years 2005 and 2007). Thus, one-peak values are found to be consistent with high maximum snow cover periods, which is not the case for the two-peak ones. In other words, a year with one-peak values often represents large and remarkable area of snow cover in this year.

The general trend of snow cover area (Fig. 4) does not show any remarkable descending or ascending behaviour, and it appears with regular oscillations among the investigated years. This is consistent with the rainfall rate in Lebanon, which was investigated over the last 45 years and no remarkable change has been recorded [1]. Besides, the investigated snow cover area over the same time period (last 45 years) showed a decrease in snow cover area between 250$300 \mathrm{~km}^{2}$ [14]. Nevertheless, the later analysis was dependant on old satellite images of different data sources and dates. In addition, there was one satellite images for a unique day over a whole year, which might not give the real values of snow cover year in other days of the same year. Therefore, the figure was not creditable.

From the analysed daily MODIS data, it was estimated that the average snowing days ranges between 65-70 days per year. While, other researchers put the average snowing days in Lebanon at 82 days per year [15]. This is totally controlled by the altitude above sea level. Therefore, the number of snowing days are distributed as: <1, 1-2, 3-4, 15-16, 37-38 and $>65$ days/year for the altitudes: $<500 \mathrm{~m}, 500-1000 \mathrm{~m}$, $1000-1500 \mathrm{~m}, 1500-2000 \mathrm{~m}, 2000-2500 \mathrm{~m}$ and $>2500 \mathrm{~m}$; respectively. The number of snowing days contributes to the total water volume derived from snow, and it also depends on snowing intensity and snow density (water content among the snowpack). 
Table 2. Estimated water volume derived from snow in Lebanon.

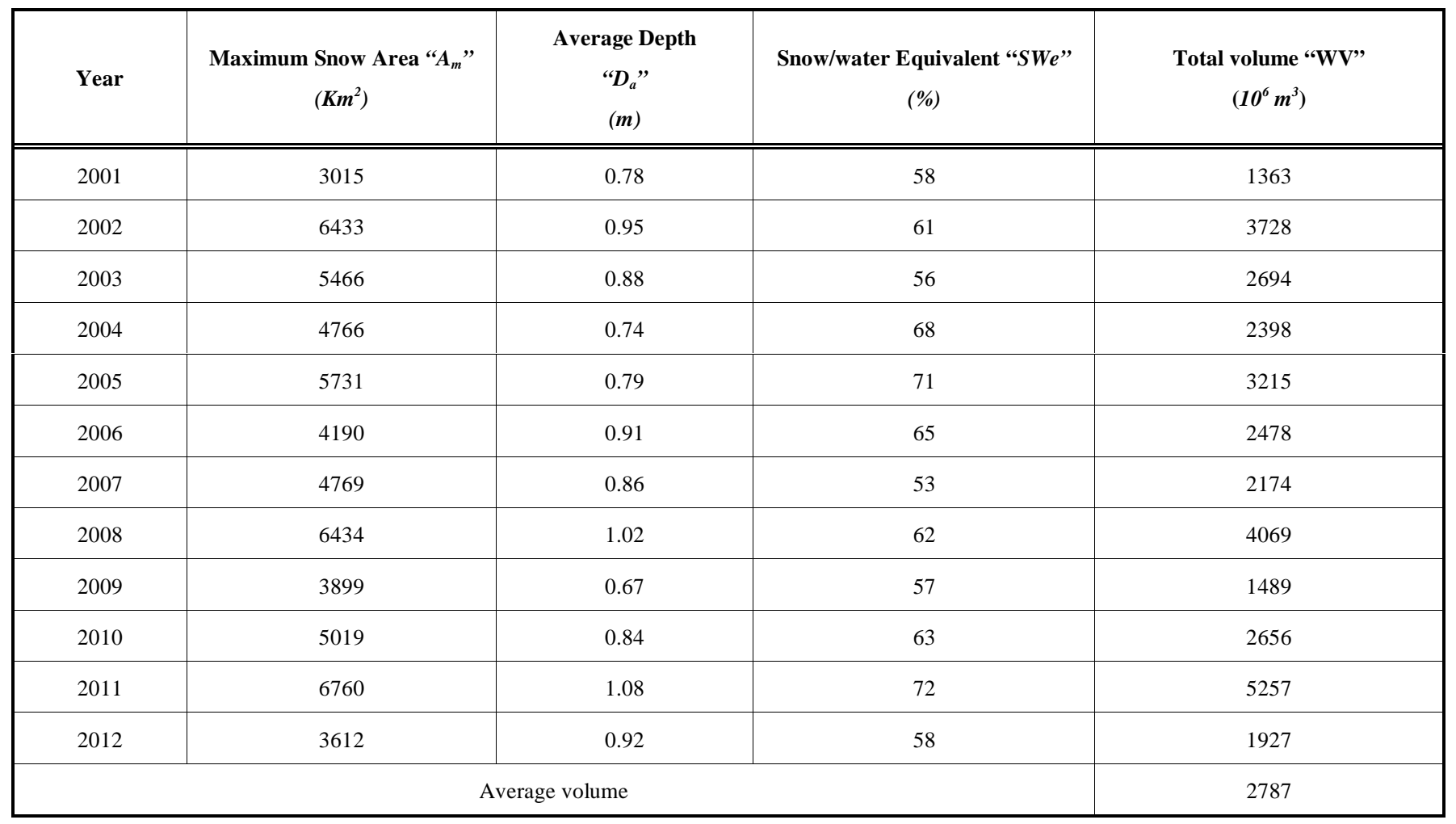

The number of snowing days in Lebanon is considered as large since there are between 37-38 days per year over the altitude above $2000-2500 \mathrm{~m}$. This almost extends on localities where carbonate rock masses (i.e. high mountains) exist and these rock masses represent the major groundwater reservoir, such as in localities of Sannine, Farya, etc. Therefore, it is well pronounced that snow contributes to a large part in the discharge of rivers and springs, as well as it has a substantial input in recharging groundwater reservoirs [16]. This was evidenced by Abd EL-Al (1953) [3] when he estimated that more than $60 \%$ of Ibrahim River water is derived from snowmelt. Also, Shaban et al., (2004) [4] estimated that 1100 million $\mathrm{m}^{3}$ of water is resulted from snowmelt on Mount-Lebanon annually.

The significantinput of snow in replenishing water sources in Lebanon has been also demonstrated in this study. Therefore, in this study the total volume of water derived from snowmelt was estimated in order to deduce the contribution of snow to the water budget in Lebanon. This has been applied for the investigated time interval (July 2000 and June 2012). Thus, the measures were calculated for each year separately, following the equation illustrated in section 2.2. Therefore, the results were plotted in Table 2. They show that the average water volume derived from snow is about 2787 million $\mathrm{m}^{3}$ per year, which is equivalent to about $58.5 \%$ of water volume in rivers and springs in Lebanon.

\subsection{Melting Rate and Patterns}

In a mountainous region like Lebanon, the snow melt regime has essential contribution to the major hydrological processes including the run-off in springs and rivers, as well as the discharge from groundwater reservoirs. If climate has changes, this contribution may change accordingly. However, the increased melting rate is proportional with the runoff rate, but it affects the residence (i.e. duration) time of water flow.

The slow, uniform and long-term duration of snow melt is much more potential for water recharge and storage, and thus it enables better utilization of water resources. In Lebanon, the existence of snow is the principal source of water; otherwise, there will be no permanent watercourses and water in rivers, springs and groundwater reservoirs will be minimal.

The melting rate (or speed) of snowpack could be identically measured in the field as discussed in the method previously; by which the reduction of snow area per unit time was determined in selected sites. Hence, the volume of snowpack in the three restricted localities was measured over three sequential weeks, and then the snow density was accounted to determine the melting rate in $\mathrm{m}^{3} /$ day and then $\mathrm{m} l / \mathrm{sec}$ (Table 3).

The obtained results, from the applied filed experiments on the selected sites on the high mountains in Lebanon, show that the melting rate ranges between 2 and $9 \mathrm{ml} / \mathrm{sec}$, averaging at about $6.28 \mathrm{ml} / \mathrm{sec}$ where the changing (i.e. reduction) area of snowpack was a major variable in this experiment. The sublimation rate must be accounted, but due to the dominant cloudy positioning of the investigated sites and their limited surface area, thus sublimation was neglected, in addition, the sublimation may be much less than amounts of evaporation and precipitation. Hence, it is obvious that the melting rate in the three sites is controlled by the altitude, which governs air temperature, and thus the site of higher altitude $(2989 \mathrm{~m})$ shows a melting rate of $2.071 / \mathrm{sec}$, while the 
Table 3. Snowpack melting rate as calculated in the field in representative sites.

\begin{tabular}{|c|c|c|c|c|c|c|c|c|}
\hline \multirow{2}{*}{ Site } & \multirow{2}{*}{ Coordinates } & \multirow{2}{*}{ Altitude } & \multirow{2}{*}{ Site Description } & \multicolumn{3}{|c|}{$\operatorname{Area}\left(\mathbf{m}^{3}\right)$} & \multicolumn{2}{|c|}{ Melting Rate } \\
\hline & & & & $1^{\text {st }}$ week & $2^{\text {nd }}$ week & $3^{\text {rd }}$ week & $\mathbf{m}^{3} /$ day & $\mathrm{ml} / \mathrm{sec}$ \\
\hline 1 & $\begin{array}{l}34^{\circ} 17^{\prime} 35^{\prime \prime} \\
36^{\circ} 07^{\prime} 39^{\prime \prime}\end{array}$ & $2989 \mathrm{~m}$ & $\begin{array}{l}\text { Exposed to sun light, alluvial } \\
\text { deposits, } 3-5 \% \text { slope }\end{array}$ & 8.12 & 6.75 & 5.61 & 0.179 & 2.07 \\
\hline 2 & $\begin{array}{l}34^{\circ} 13^{\prime} 28^{\prime \prime} \\
36^{\circ} 06^{\prime} 31^{\prime \prime}\end{array}$ & $2929 m$ & Shaded, limestone, 6-9\% slope & 15.66 & 11.73 & 6.32 & 0.666 & 7.70 \\
\hline 3 & $\begin{array}{l}34^{\circ} 14^{\prime} 55^{\prime \prime} \\
36^{\circ} 05^{\prime} 33^{\prime \prime}\end{array}$ & $2887 \mathrm{~m}$ & $\begin{array}{l}\text { Partially exposed to sunlight, } \\
\text { fragmented rocks, } 10-12 \% \text { slope }\end{array}$ & 18.50 & 15.61 & 7.52 & 0.784 & 9.07 \\
\hline \multicolumn{4}{|c|}{ Average } & 14.26 & 11.36 & 6.48 & 0.543 & 6.28 \\
\hline
\end{tabular}

relatively lower one $(2887 \mathrm{~m})$ is $9.071 / \mathrm{sec}$. This is almost realistic value since the measured snowmelt rate by satellite images for the entire Lebanon was estimated at $16.7 \mathrm{~m} / / \mathrm{sec}$ [17]. The later was estimated by calculating the ratio between the duration of snow accumulation to the duration of snow melting has been decreased lately. Thus, the melting duration has been decreased in the last three decades [1]. This has been noticed the field surveys carried out on different snowpack localities in Lebanon where it was estimated that the area of snowpack is decreased (i.e. due to melting and sublimation) by about $10-15 \%$ each 10 days, which was applied for a unique year of the experiment.

The other part of the snowpack melting concerns with the melting patterns or shapes which are indicative to the melting regime and it is controlled by two main factors: 1) the meteorological factors including air temperature (functioned by sunlight radiation) and wind; 2) terrain factors with a special emphasis to slope, rock lithology and sunlight exposure.

During the achieved work over the three years, all existed snowpack patterns were reported and then correlated to the above mentioned factors (i.e. meteorological and terrain characteristics). Therefore, the melting of the snowpack was found to attribute to three major categories as investigated in the applied filed surveys on the Lebanese mountains. They can be summarized as follows:

- $\quad$ Longitudinal melting patterns, which are represented by elongated channels in snowpack along which melting routes are detached.

- Dissipated and dots patterns which appear as nodes and spaces on snowpack surface.

- Shaped surfaces that show a miscellany of snowpack morphologies.

These major categories include nine snowpack patterns and they were investigated directly in the field to identify their behaviour and characteristics with a special emphasis to the melting regime and rate. Table 4 shows the recognized snowpack patterns and the resulting related information which was concluded over the three years investigation at different altitudes and terrain characteristics. These were measured on the 275 studies localities.

The elongated patterns have three major aspects of longitudinal shapes since the common melting processes along sloping terrain follow linear dissolution of the snowpack surfaces. They are well pronounced during late summer composing old snow that may be covered by the snow of the next year, as it has been frequently happened on the elevated areas above $2800 \mathrm{~m}$ in Lebanon. Also, they are more or less occurring over the carbonate rocks (limestone and dolomite) which compose the highest mountain peaks in Lebanon. The melting process is always characterized by high rate, because these remain for long time exposed to the summer sunlight. Hence, melting along the elongated patterns discharge into at foot slope zones and running water as rills is often developed.

The dissipated and dotted snowpack patterns represent isolated melting patches (spaces) or picks on the snowpack surface. They are created due to the presence of rugged surfaces below the snowpack, which are mostly covered by rocks and other terrain objects. These surfaces act in melting the snow since they capture heat inside, such as rocks, shrubs, etc.

These aspects were noticed at different meteorological terrain characteristic. Thus, the area of the isolated (dissipated) melting patches increases as the temperature increases and they become open to each other and then connected until snowpack is totally disappeared. Consequently, the melting processes are developed laterally and vertically, and they usually result water flow.

In terms of areal extent, the most dominant aspect of snowpack patterns are those related to the shaped category, because they mostly spread on relatively low sloping lands and occupy several hundreds of square meters. Therefore, they are affected by the objects on terrain surface, notably when they exist with shallow depths. In this aspect and due to the relatively gentle sloping and flat surfaces; however, the melting water from snowpack mostly percolates downward into the underlying stratum, and the run-off water is found to be minimal. This aspect of patterns often lasts until late summer and may be covered by the new snow of the year after.

\section{CONCLUSION}

Water shortage has become a serious problem since water resources become under stress and the developed challenges whether by the natural factors or from the negative human 
Table 4. Major recognized snowpack patterns in Lebanon.

\begin{tabular}{|c|c|c|c|c|c|c|c|}
\hline Snowpack Category & Snowpack Pattern & Altitude & Timing & Slope & $\begin{array}{l}\text { Sunlight } \\
\text { Exposure }\end{array}$ & Temperature & Lithology \\
\hline \multirow{3}{*}{ Longitudinal } & Longitudinal furrow along valleys & $\mathrm{H}$ & LS & SS & $\mathrm{E}$ & $\mathrm{H}$ & $\mathrm{CR}$ \\
\hline & Linears on steep slope with stony terrain & M-H & LS & SS & $\mathrm{Ud}$ & $\mathrm{M}-\mathrm{H}$ & SR \\
\hline & Hinges accumulation on previous snow & $\mathrm{H}$ & LS & SS & SE & $\mathrm{M}-\mathrm{H}$ & $\mathrm{CR}$ \\
\hline \multirow{4}{*}{ Dissipated and dots } & Pits on rugged terrain & L-M & MW & F-M & SE & M-H & $\mathrm{AV}$ \\
\hline & Snow shrinking due to fast sunlight heat & $\mathrm{L}$ & MW & $\mathrm{F}$ & $\mathrm{Ud}$ & $\mathrm{H}$ & $\mathrm{AV}$ \\
\hline & Cavity melting due to collapsed snow masses & $\mathrm{H}$ & LS & F-M & SE & $\mathrm{M}-\mathrm{H}$ & HR \\
\hline & Contact melting along rocks and roads & L-H & AL & $\mathrm{F}$ & SE & $\mathrm{H}$ & HB \\
\hline \multirow{2}{*}{ Shaped } & Ripples due to overlain snow accumulation & M-H & LS & $\mathrm{F}$ & $\mathrm{E}$ & $\mathrm{M}-\mathrm{H}$ & $\mathrm{Ud}$ \\
\hline & Chaotic aspect on dry shrubs & L-M & MW & F-M & SE & $\mathrm{H}$ & SR \\
\hline
\end{tabular}

$\mathrm{H}=$ high altitude $(>2750 \mathrm{~m}) ; \mathrm{M}=$ moderate $(1500-2750 \mathrm{~m}) ; \mathrm{L}=$ low $(<1500 \mathrm{~m}), \mathrm{Ud}=$ undefined

$\mathrm{LS}=$ late summer; $\mathrm{AL}=$ all times; $\mathrm{MW}=$ moderate weather.

$\mathrm{SS}=$ steep slope $; \mathrm{F}=$ flat $; \mathrm{F}-\mathrm{M}=$ flat to moderate.

$\mathrm{E}=$ exposed; $\mathrm{SE}=$ slightly exposed.

$\mathrm{H}=$ high temperature $\left(>28^{\circ} \mathrm{C}\right) ; \mathrm{M}=$ moderate $\left(22-28^{\circ} \mathrm{C}\right)$.

$\mathrm{CR}=$ carbonate rocks; $\mathrm{HB}=$ hard bodies; $\mathrm{SR}=$ soft rocks; $\mathrm{HR}=$ hard rocks; $\mathrm{AV}=$ alluviums

interference. However, aspects of water resources are different between regions, and thus some of these resources exist in one region but do not so in the other. The existence of water depends on the natural setting of any region worldwide, including mainly the geomorphology, geology and then the meteorology, which are governing the generation and journey of water.

Even though, Lebanon is a small country, yet it encompasses all aspects of water resources. Hence, the mountainous geomorphology of Lebanon results remarkable meteorological barrier that restricts considerable volume of water as precipitation. In addition, the geological setting provides defined environment for different aspects of water flow, storage and accumulation where snow is one of these aspects. Thus, snow remains a white cover over vast area exceeding $1 / 4$ of Lebanon for couple of months, mostly more than ten months.

Recently, there has been a great concern given to snowpack since it was believed that snow remains a permanent feeding water sources. For this purpose, new techniques of remote sensing have been applied since it can provide comprehensive observation and thus monitoring procedures for snow cover. These techniques are usually supported by field verification and geo-information system analysis [18-23].

In Lebanon, snow cover remained neither discovered nor investigated for long decades, and it was viewed only as a site for tourism. However, the lately existed water shortage accompanied with understanding of snow importance as a source of water makes it clue for investigation by many researchers. Therefore, it is believed that snow is the primary source of water in Lebanon, and without snow over the mountain chains, the largest number of water resources in Lebanon will not appear anymore. This motivated the authors dedicating long time working in the field of snow hydrology and monitoring on the Lebanese mountains. Therefore, the authors demonstrated several scientific re- leases and works on the subject matter. They carried out filed survey on the snow pack extends along the Lebanese mountain ridges. The field survey was combined with satellite images analysis to determine the changing trends in snow cover area with respect to field measures. Thus, satellite observations provide information of the aspect of snow distribution and accumulation/de-accumulation regime, while field measures, as supporting implementation, helped in the details field measure and the confirmation of data reliability obtained from satellite images,

Accordingly, this study presents the major findings that were resulted from the field survey and the joined remotely sensed geo-spatial data. It shows that there is a general periodicity in the distribution of snow cover, which may have one and sometime two peaks of large-scale snow storms. Thus, it was clear that the accumulation of snow has much more residence time than the dissolution (i.e. melting or deaccumulation), as a result of the recently existed high temperature impact. However, there is no clear evidence of any descending trend in the snow cover area over the investigated period between 2001 and 2012 in Lebanon. Thus, it is still believed that the amount of solid precipitation (snowfall) has not substantially changed, but there is an increased melting rate due to the increased temperature as it was estimated at about $1.8^{\circ} \mathrm{C}[1]$.

With respects to the estimation of the melting rate (i.e. $6.28 \mathrm{ml} / \mathrm{sec}$ ); however, it can be considered as high rate, notably that this rate is exaggerated when the snowpack is directly exposed to sunlight radiation. This was also evidenced by the amount of running water in late summer, which is enhanced by the dominant sloping terrain that characterizes the mountainous Lebanese territory. The recently increased melting rate could be identified from the new existed surface channels and rills which have been dug by the running water from the increased bulk of melting water. It is considered as a climatic-controlled hydrologic process. Nevertheless, the 
newly interference of human activities accelerates the snow melting process, in addition to the pollution aspects that are resulted from these activities.

Moreover, the shapes that are formed during the melting process were investigated and classified into different categories and aspects. Each aspect characterizes defined behaviour of melting mechanism. They show a miscellany of controls for the lateral and vertical movement of the melting water from snowpack. These aspects can be well utilized during the determination of water harvesting (e.g. construction of mountain lakes, etc.) sites since they explain the flow mechanism of running water.

Yet, more detailed and long-term field investigations are required to determine the behaviour of snowpack and its melting regime and geographic distribution in space and time. Also, new strategies are needed to conserve the snow cover zones on the high mountains of Lebanon which comprise the main feeding source for groundwater reservoirs, thus there must be new plans to consider these zones as natural reserved areas.

\section{CONFLICT OF INTEREST}

The authors confirm that this article content has no conflict of interest.

\section{ACKNOWLEDGEMENTS}

This paper is one of the outputs that resulted from the research project funded by the National Council for Scientific Research (CNRSL) in Lebanon. Thus, the authors would like to extend the acknowledgement and great appreciations to the CNRSL for the kind support and frequent encouragement for research and scientific development.. Appreciations are also extended to the Centre d'Etudes Spatiales de la Biosphère (CESBIO), the French Institute which introduces frequent help, notably in the use of new satellite techniques for water resources assessment in Lebanon.

\section{REFERENCES}

[1] Shaban A. Analyzing climatic and hydrologic trends in Lebanon. J Environ Sci Eng, 2011; 3(5): 483-92.

[2] Fawaz M. Towards a water policy in Lebanon. Beirut, Lebanon, ESIB (In Arabic): 2007; p 259.

[3] Abd EL-Al, I. Statics and dynamics of water in the Syro-Lebanese limestone massif. Ankara symposium on arid zone hydrology, UNESCO: Ankara, Turkey, 1953; pp. 60-76.

[4] Shaban A, Faour G, Khawlie M, Abdullah C. Remote sensing application to estimate the volume of water in the form of snow on Mount Lebanon. Hydrol Sci J 2004; 49(4): 643-53.
[5] Shaban A, Darwich T. Climate Change and anthropogenic impact on water resources of the Lebanese coast. UNESCO Int. Hydrological; Programme. $2^{\text {nd }}$ Int. Symposium on: building knowledge bridges for sustainable water futures, 2011.

[6] Matzler C. Microwave permittivity of dry snow. IEEE Trans. Geosci Remote Sens 1996; 34(2): 573-81.

[7] Wiesinger T, Schweizer J. Snow profile interpretation. Proceedings of the International Snow Sciences workshop. Big Sky, MT. 2000; pp. 223-9.

[8] Kaser G. The International Classification of seasonal snow on ground. Technical document in Hydrology. 2009; (83), and IACS contribution No.1, pp. 90.

[9] De Quervain R. The strength properties of the snow cover and its measurement. Geophy Appl 1950; 8, pp. 13-5 (In German).

[10] Gomez-Landesa E, Rango A. Assessment of MODIS channels 1and 2 snow cover mapping capability. EOS Trans Am Geophys Union 2000; 81(48): F548.

[11] Brown L, Thorne R, Woo M. Using satellite imagery to validate snow distribution simulated by a hydrological model in large northern basins. Hydrol Processes 2008; 22(15): 2777-87.

[12] Christopher G, Fletcher C, Zhou H, Kushner P, Fernandes R. Using models and satellite observations to evaluate the strength of snow albedo feedback. J Geophys Res, 2012; 117(11): DOI: 10.1029/2012JD017724

[13] Riggs G, Hall D, Salomonson V. MODIS snow products. 2006, Available at: http://nsidc.org/data/docs/daac/modis_v5/dorothy_snow_doc.pdf

[14] Shaban A. Indicators and aspects of hydrological drought in Lebanon. Water Resour Manag J 2009; 23: 1875-91.

[15] Mhawej M, Faour G, Shaban A. Toward an enhanced method of identifying snow water equivalent and studying snow cover characteristics in Lebanon. J Remote Sens Environ 2013 (In Press)

[16] Darwich T, Shaban A, Portoghese I, et al. Using remotely sensed data to induce snow cover dynamics and water productivity for sustainable water management in Ibrahim River Basin, Lebanon. First CIGR Inter-regional Conference on Land and Water Challenges, Bari, Italy 10-14 September, 2013.

[17] Telesca L, Shaban A, Drapeau L, Darwich T, El-Hage M, Faour G. Use of Singular Spectrum Analysis to Diagnose Long-term satellite monitoring of Snow Cover on Mountain Chains in Lebanon, 2013. [submitted to Acta Geophysica].

[18] Wang X, Xie H. New methods for studying the spatiotemporal variations of snow cover based on combination products of MODIS Terra and Aqua. J Hydrol 2009; 371:192-200.

[19] Zeinivand H, De Smedth F. Hydrological modelling of snow accumulation and melting on river basin scale. Water Resour Manag 2009; 23: 2271-87.

[20] Ellis C, Pomeray J, Brown T, MacDonald J. Simulation of snow accumulation and melt in needle-leaf forest environments. Hydrol Earth Syst Sci 2010; 14: 925-40.

[21] Martelloni G, Segoni S, Lagomarsino D, Fanti R, Catani F. Snow accumulation/melting model (SAMM) for integrated use in regional scale landslide early warning systems. Hydrol Earth Syst Sci 2013; 17: 1229-40.

[22] Zahabiyoun B, Goodarzi M B, Bavani A, and Azamathulla H. Assessment of Climate Change Impact on the Gharesou River Basin Using SWAT Hydrological Model. Clean - Soil, Air, Water, 2013; 41(6): 601-9.

[23] Zhou H, Aizen E, Aizen V. Deriving long term snow cover extent dataset from AVHRR and MODIS data: Central Asia case study. Remote Sens Environ 2013; 136: 146-62.

(C) Shaban et al.; Licensee Bentham Open.

This is an open access article licensed under the terms of the Creative Commons Attribution Non-Commercial License (http://creativecommons.org/licenses/by-nc/3.0/) which permits unrestricted, non-commercial use, distribution and reproduction in any medium, provided the work is properly cited. 